\title{
Sexually transmitted infections in male heterosexual Dutch clients who visited a cross-border female sex worker; a 3 year retrospective study
}

\section{CJG Kampman1, CJPA Hoebe2,3, R Koene4, LA Kamp5, K Jansen ${ }^{6}$, FDH Koedijk ${ }^{1}$, A Tostmann ${ }^{5}$, JLA Hautvast ${ }^{5}$}

1. Public Health Service Twente, Enschede, The Netherlands, 2. Public Health Service South Limburg, Heerlen, The Netherlands, 3. Maastricht University Medical Center (MUMC+), Faculty of Health, Medicine and Life Sciences, Department of Medical Microbiology, Care and Public Health Research Institute Maastricht, The Netherlands, 4. Public Health Service Gelderland Zuid, Nijmegen, The Netherlands, 5. Department of Primary and Community Care,

Radboud university medical centre, Nijmegen, The Netherlands, 6. Robert Koch Institute, Berlin, Germany

\section{INTRODUCTION}

- Dutch male heterosexual clients report to visit crossborder Female Sex Workers (FSW), and may therefore be at risk for sexually transmitted infections (STI).

\section{AIM}

- The aim of this study was to assess whether having commercial cross-border sex is associated with being diagnosed with an STI more frequently than visiting an Dutch FSW

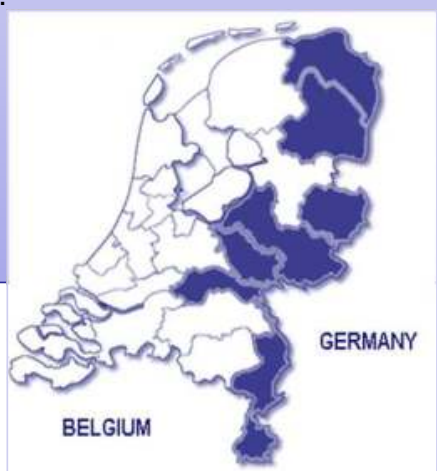

Figure 1. Counties with STI clinics participating in current study (in purple)

\section{METHODS}

- An observational retrospective study was performed using patient-based data of 8 Dutch STI clinics bordering Germany (see figure 1), between 2011-2013.

- All male heterosexual clients of FSWs were selected and data on country of visiting FSW and occurrence of STI were used.

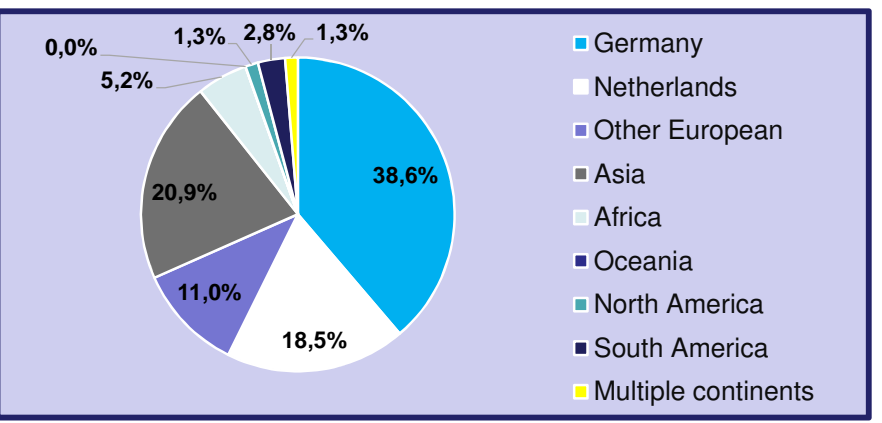

Figure 2. Visited countries by clients of FSW

\section{RESULTS}

- 535 clients had a known country of visit.

- Making cross-border visits to Germany was most frequently reported (38.7\%), followed by visits to Asia (20.9\%) and within the Netherlands (18.5\%), see figure 2.

- STI positivity was $15 \%$ among clients making cross-border visits, $7.9 \%$ among clients visiting another country and $7.1 \%$ among clients who visited the Netherlands.

- In multivariable analysis (see table below) clients were more likely to be STI positive when they had 20 or more partners $(\mathrm{OR}=3.5 ; 95 \% \mathrm{Cl} 1.4$ to 8.6$)$ in the last 6 months and did not use a condom during last sexual contact $(\mathrm{OR}=2.3 ; 95 \% \mathrm{Cl} 1.2$ to 4.3$)$.

Table. Demographic and behavioral predictors for STI positivity among clients

\begin{tabular}{|c|c|c|}
\hline & $\begin{array}{r}\text { Univariable } \\
\text { regression } \\
\text { analysis } \\
\text { OR }(95 \% \mathrm{Cl})\end{array}$ & $\begin{array}{r}\text { Multivariable } \\
\text { regression } \\
\text { analysis } \\
\text { OR(95\%) }\end{array}$ \\
\hline \multicolumn{3}{|l|}{ Age } \\
\hline$<25$ years & ref & nt \\
\hline $25-44$ years & $0.9(0.4-1.8)$ & \\
\hline$>45$ years & $1.1(0.5-2.5)$ & \\
\hline Country of birth & & \\
\hline Netherlands & ref & ref \\
\hline Other & $0.4(0.1-1.1)$ & $0.4(0.1-1.2)$ \\
\hline \multicolumn{3}{|l|}{ No. of sex partners } \\
\hline $0-2$ & ref & ref \\
\hline $3-5$ & $1.7(0.8-3.6)$ & $1.7(0.8-3.6)$ \\
\hline $6-20$ & $1.8(0.8-4.1)$ & $1.6(0.7-3.9)$ \\
\hline$>20$ & $3.7(1.5-9.0)$ & $3.5(1.4-8.6)$ \\
\hline \multicolumn{3}{|l|}{ Condom use } \\
\hline Yes & ref & ref \\
\hline No & $2.1(1.2-3.9)$ & $2.3(1.2-4.3)$ \\
\hline \multicolumn{3}{|l|}{ Sex abroad } \\
\hline No & ref & ref \\
\hline Yes, cross-border & $2.4(1.0-5.6)$ & $2.1(0.9-5.2)$ \\
\hline Yes, another country & $1.1(0.4-2.7)$ & $1.0(0.4-2.5)$ \\
\hline
\end{tabular}

\section{CONCLUSIONS and RECOMMENDATIONS}

- Country of visit does not appear to be a risk factor for STI in clients of FSW.

- STI prevention advice should remain focused on reduction of multiple partners and adequate condom use. 